\title{
Laparoscopic Living Donor Left Lateral Sectionectomy: A New Standard Practice for Donor Hepatectomy: "A Word of Caution"
}

\author{
Sable SA* \\ Department of Surgical Gastroenterology, Liver \\ Transplant Surgery and Minimal Access Surgery, \\ Kokilaben Dhirubhai Ambani Hospital, India \\ *Corresponding author: Shailesh Sable, Department \\ of Surgical Gastroenterology, Liver Transplant Surgery, \\ Minimal Access Surgery, Kokilaben Dhirubhai Ambani \\ Hospital, Mumbai, India
}

Received: December 04, 2017; Accepted: December 12, 2017; Published: December 19, 2017

\section{Editorial}

Laparoscopic surgery has definitely proven to be beneficial from cosmesis, analgesic and length of stay point of view. But its application for donor liver surgery needs a special attention. Donor safety is primary concern in living donor liver transplantation. Donor hepatectomy (LLS) should not be viewed purely from technical point of view. Comparison between Laparoscopic left lateral sectionectomy (LLLS) and Laparoscopic Donor Nephrectomise (LDN) is very unfair [1]. Laparoscopic donor nephrectomy (LDN) itself has no clear cut advantages in living donor kidney transplantation. There are no level I evidence to suggest that Laparoscopic Donor Nephrectomy (LDN) is better than Open Donor Nephrectomy (ODN) [2-4].

LLLS is a complex procedure and morbidity related to it has completely different implications as compared to LDN. Most of the studies comparing laparoscopic versus open left lateral sectionectomy were either for benign or malignant liver lesions. Extrapolating this data to living donors should be viewed with caution. S.G lee et al has reported a small group of patients comparing Laparoscopic LLS verus Open LLS, they reported only one minor complication(wound seroma) [5], however authors current study reports $17.9 \%$ complication rates in LLLS group of which 6 were grade III probably very high to consider it as a standard procedure. We also feel that 2 patients in authors group had two grade III complications (Bladder injury \& suprapubic hematoma) which are related to procedure itself and would have not occurred otherwise in conventional open LLS. Adding morbidity secondary to a new procedure should be viewed with caution.

Biliary anastomosis is considered as Achilles' heel in liver transplantation. Biliary complication rate in the current study ${ }^{1}$ is reasonably high (3\%) for left lateral sectionectomy, especially Grade IIIb (Requiring re-explorations in 2 patients and ERCP with stenting in one) and one grade II (Right anterior bile duct stenosis). Intraop cholangiogram could have identified biliary anatomical variations/ leak and these complications could have been averted. Decision to divide bile duct is a critical one in left lateral sectionectomy and we feel that it should be based on intra-op cholangiogram. Using metal clips to secure bile duct stumps has its own disadvantages; simple silk suture may be a better option.

Vascular injury during laparoscopic liver surgery can be fatal; it either leads to massive haemorrhage or air embolism. Laparoscopically controlling/managing this complication needs special skills, and may be difficult for experienced surgeon too. Laparoscopic vascular controlling modalities is still a matter of debate, we need to have some consensus to avoid vascular complications. Clavien Dindo classification or Comprehensive Complication Index (CCI) [6] doesn't consider intra-op complications, which we feel is a drawback of this score designs. Recommending a new procedure/approach based only on this scores/indices that to comparing it with a different entity may be inappropriate considering the safety of donor. Recently Bekheit $\mathrm{M}$ et al. also concluded that laparoscopic liver procurement in live donor could be as safe as conventional open approach, but this data needs to be viewed with caution $[7,8]$. Majority of the studies included in this review were either retrospective or none randomised. They also fail to report any near miss events or intraoperative events which could jeopardise donor safety. Authors failed to give any robust conclusions based on this review [8].

In conclusion, laparoscopic living donor left lateral sectionectomy is technically feasible but its safety needs to be confirmed in larger head to head multicentric study.

\section{References}

1. Soubrane O, de Rougemont O, Kim KH, Samstein B, Mamode N, Boillot O, et al. Laparoscopic Living Donor Left Lateral Sectionectomy: A New Standard Practice for Donor Hepatectomy. Ann Surg. 2015; 262: 757-763.

2. European Renal Best Practice Guideline on the Management and Evaluation of the Living Kidney Donor and Recipient. NDT. 28; S2: ii1-ii71.

3. The British Transplant Society and the Renal Association. The United Kingdom Guidelines for Living Donor Kidney Transplantation. Third Edition.

4. Kidney Health Australia - Caring for Australians with Renal Impairment. Published in Nephrology. 2010; 15: S72-S145.

5. Kim KH, Jung DH, Park KM, Lee YJ, Kim DY, Kim KM, et al. Comparison of open and laparoscopic live donor left lateral sectionectomy. Br J Surg. 2011; 98: 1302-1308.

6. Slankamenac K, Graf R, Barkun J, Puhan MA, Clavien PA. The Comprehensive complication Index. A novel continuous scal to measure surgical morbidity. Ann Surg. 2013; 258: 1-7.

7. Carswell KA, Sagias FG, Murgtroyd B, Rela M, Heaton N, Patel AG. Laparoscopic versus open left lateral segmentectomy. BMC surg. 2009; 9: 14.

8. Bekheit M, Khafagy PA, Bucur P, Katri K, Elgendi A, Abdel-Salam W, et al. Donor safety in live donor laparoscopic liver procurement: systematic review and meta-analysis. Surg Endosc. 2015; 29: 3047-3064. 